\title{
Enhancing phosphorus recovery by a new internal recycle seeding MAP reactor
}

\author{
Zhigang Liu ${ }^{\mathrm{a}}$, Qingliang Zhao ${ }^{\mathrm{a}, *}$, Duu-Jong Lee ${ }^{\mathrm{b}}$, Nan Yang ${ }^{\mathrm{a}}$ \\ ${ }^{a}$ State Key Lab of Urban Water Resources and Environment (SKLUWRE), School of Municipal and Environmental Engineering, \\ Harbin Institute of Technology, Harbin 150090, China \\ ${ }^{\mathrm{b}}$ Department of Chemical Engineering, National Taiwan University, Taipei, Taiwan 10617, China
}

Received 17 August 2007; received in revised form 15 November 2007; accepted 15 November 2007

Available online 9 January 2008

\begin{abstract}
Phosphorus is a depleting resource that needs recovery from wastewater streams. The magnesium ammonium phosphate (MAP) crystallization process could simultaneously recover ammonium nitrogen and phosphorus at equal molar basis to yield slow-release MAP fertilizer. However, the present MAP processes are not efficient in recovering phosphorus at low P concentrations. This work presented and tested the performance of a newly proposed MAP reactor, the internal recycle seeding reactor (IRSR) that comprised of a reaction zone and a settling zone connecting with an internal recirculation loop. Owing to the enhanced secondary nucleation rates of MAP crystals in reaction zone under controlled circumstance, the proposed IRSR recovered $78 \%$ of phosphorus from wastewater at a low level of $21.7 \mathrm{mg}-\mathrm{P} \mathrm{L}^{-1}$. The optimal operation parameters for the IRSR were investigated with synthetic wastewater and determined as that the $\mathrm{Mg} / \mathrm{PO}_{4}^{3-}-\mathrm{P}$ molar ratio was $1.3-1.5: 1$, THRT was up to or longer than $1.14 \mathrm{~h}$, the seed concentration of reaction zone was $0.40-1.0 \mathrm{~g} \mathrm{~L}^{-1}$. Further needs for the proposed IRSR strategies were also discussed.
\end{abstract}

(c) 2007 Elsevier Ltd. All rights reserved.

Keywords: MAP; Internal recycle seeding reactor; Phosphorus recovery; Seed

\section{Introduction}

Phosphorus is a depleting resource (Steen, 1998). In addition, as a result of its consumption, it returns the environment as the waste or through wastewater, which has potential to cause eutrophication or blue green algal blooms of receiving waters. Thus, it is obligatory and necessary to remove and recover phosphorus from waste or wastewater in order to contribute toward sustainable development, alleviate the environmental pressure and meet the increasingly strict regulations for phosphorus

\footnotetext{
${ }^{*}$ Corresponding author. Tel.: +86 451 86283017; fax: +86451 86282100.

E-mail addresses: qlzhao@hit.edu.cn, zhq11962@yahoo.com.cn (Q. Zhao).
}

discharge. Recovery and removal of phosphorus from wastewater streams can be achieved via various processes, such as metal precipitation, constructed wetland systems, biological nutrient removal (BNR) processes, enhanced biological phosphorus removal (EBPR) processes, MAP (magnesium ammonium phosphate) crystallization process, and others (de-Bashan and Bashan, 2004). Among these processes, the magnesium ammonium phosphate (MAP, mineralogically as struvite) crystallization has been regarded as a promising method, because it can simultaneously recover ammonium nitrogen and phosphorus at equal molar basis to yield slow-release MAP fertilizer (Li and Zhao, 2003).

Process parameters and mechanisms of MAP crystallization were conducted and summarized (Battistoni et al., 2002; Doyle and Parsons, 2002; Jaffer et al., 2002). Studies had been performed to realize effects of numerous process 
parameters on MAP performance, including $\mathrm{pH}$ (Ohlinger et al., 1998; Mijangos et al., 2004), reactant origins (Chimenos et al., 2003; Yang and Sun, 2004), molar ratios of $\mathrm{Mg} / \mathrm{N} / \mathrm{P}$ (Altinbas et al., 2002), temperature (Mijangos et al., 2004), the presence of foreign ions (Le Corre et al., 2005; Kabdaşli et al., 2006), and mixing energy (Ohlinger et al., 1999). MAP crystallization is applied to treat phosphorus or ammonium nitrogen laden wastewaters (Battistoni et al., 2002; Li and Zhao, 2002, 2003; Lee et al., 2003; Kim et al., 2004; Quintana et al., 2004; Tunay et al., 2004; Wu and Bishop, 2004) and separated human urine (Ban and Dave, 2004). Three types of batch reactors were adopted with sufficient phosphorus recovery: mechanically stirring reactor (MSR) (Stratful et al., 2004; Yoshino et al., 2003), air agitated fluidized bed reactor (AAFBR) (Jaffer et al., 2002; Le Corre et al., 2007a), and water agitated fluidized bed reactor (WAFBR) (Battistoni et al., 2000, 2001; Adnan et al., 2003). The configuration and operation of MSR is simple, but consumes considerable amount of mixing energy ( $\mathrm{Wu}$ and Bishop, 2004). Struvite crystals can grow rapidly in the AAFBR and WAFBR, however, the corresponding energy demand is also high (Battistoni et al., 2005). Additionally, large MAP crystals thus formed are not only poorly fluidized in the reactors, but also reduce MAP recovery owing to low surface area (Shimamura et al., 2001). Suzuki et al. (2007) and Le Corre et al. (2007b) recently inserted stainless steel meshes in the upper section of AAFBR to reduce energy demand and to minimize fines remaining in solution, thereby enhancing phosphorus recovery. Shimamura et al. (2003) devised a two-tank reactor to keep MAP crystal size constant in the reaction tank and phosphorus recovery efficiency stable.

Difficulties were noted to operate these MAP reactors. Suzuki et al. (2007) and Le Corre et al. (2007b) demonstrated the quantity of struvite crystal needed in the reaction zone was hard to control. Suzuki et al. (2007) noted shortcut flow between reaction zone and precipitation zone in the reactor reduced recovery efficiency. Moreover, reactor proposed by Le Corre et al. (2007b) and Shimamura et al. (2003) required external recirculation loops to fluidize and recycle seed crystals, respectively. To overcome the mentioned difficulties, in this study, a new MAP reactor, namely, the internal recycle seeding reactor (IRSR), was proposed and its effect and operation performance in phosphorus recovery from wastewater were tested and determined, in order to provide a potential and practical reactor used in the future for phosphorus recovery from wastewater. Burns et al. (2003) and Adnan et al. (2004) claimed that crystal seeding strategy insignificantly affected the MAP reactor performance, but $\mathrm{Wu}$ and Bishop (2004), Lee et al. (2005) and Wang et al. (2006) reported seeding could enhance the MAP reaction rate, increased crystal size and improved crystal settleability. Thus, the other objective of this work is to investigate into whether crystal seeding affects the performance of the proposed IRSR.

\section{Methods}

\subsection{Reactor design and preliminary test}

The IRSR consisted of two concentric columns (Fig. 1), with an internal column of $0.35 \mathrm{~L}$ effective volume for reaction, and an external column of $2.5 \mathrm{~L}$ effective volume for crystal sedimentation. Seed were lifted continuously by air to reaction zone to contact with wastewater for forming new MAP crystals. Then the agglomerates were settled in the external settling zone. The crystal concentration, including primary and new MAP crystals in the reaction zone, could be controlled by adjusting the circulation flow rate and the quantity of crystals at the bottom, respectively or both. The circulation flow rate of air lift pipe depended on the flow rate of main air pipe, while the crystal quantity in crystal zone was kept by discharge amounts of crystal. Three sub air pipes fixed on the inner wall of the internal column in proportional spacing provided blending power to avoid potential shortcut.

All chemicals were in analytical reagent grade and were used without further purification. The synthetic wastewater was made by mixing tap water, $\mathrm{NH}_{4} \mathrm{Cl}$, and $\mathrm{Na}_{2} \mathrm{H}$ $\mathrm{PO}_{4} \cdot 12 \mathrm{H}_{2} \mathrm{O}$ salts, whose $\mathrm{pH}$ was adjusted to $9.2-9.7$ using $\mathrm{NaOH}$. The synthetic wastewater was settled for $8-10 \mathrm{~h}$ before use to minimize the effects of $\mathrm{Ca}^{2+}, \mathrm{Mg}^{2+}$ and $\mathrm{Fe}^{3+}$ originated potentially from tap water by spontaneous precipitation at base condition. The magnesium solution was prepared using $\mathrm{MgCl} \cdot 6 \mathrm{H}_{2}$ salt due to its superiority in MAP crystallization ( $\mathrm{Le}$ and $\mathrm{Li}, 2006$ ). Both magnesium solution and synthetic wastewater were injected by peristaltic pump (YZ1515w, Baoding Longer

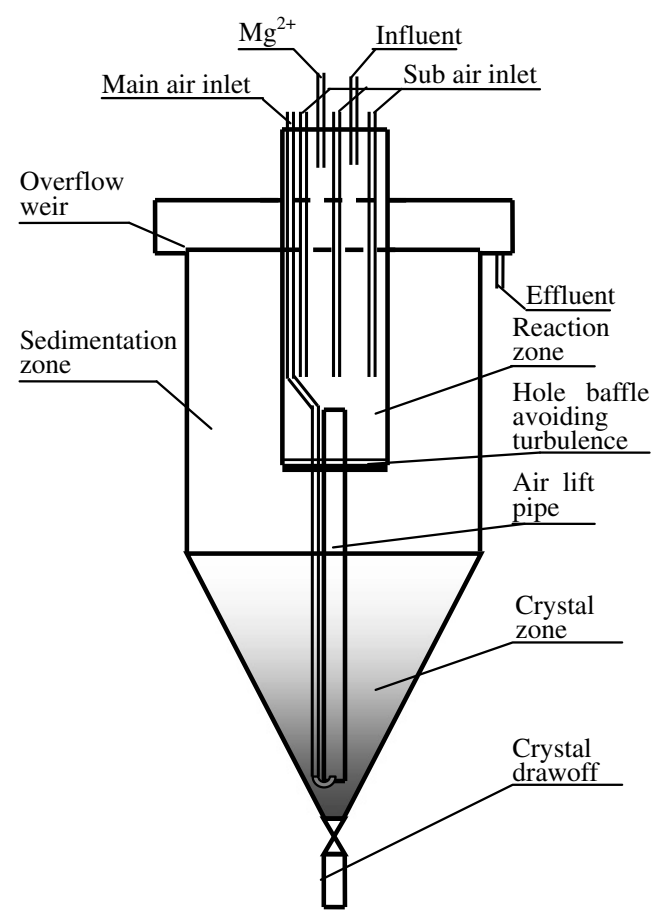

Fig. 1. Configuration of IRSR. 
Precision Pump Co., Ltd., China) quantificationally depending on the experiment design.

Table 1 lists the tested experimental conditions. Three different phosphorus concentrations were adopted and the influent flow rate was fixed at $1.25 \mathrm{~L} \mathrm{~h}^{-1}$. The molar ratios of $\mathrm{Mg} / \mathrm{PO}_{4}^{3-}-\mathrm{P}$ were achieved with magnesium solution of $0.25 \mathrm{~mol} \mathrm{~L}^{-1}$.

\subsection{Performance tests of IRSR}

Three operating conditions were investigated to determinate the performances of IRSR, respectively. In all experiments, the flow rate of main air pipe and each sub pipe were kept at $11-12 \mathrm{~L} \mathrm{~h}^{-1}$ and $1-2 \mathrm{~L} \mathrm{~h}^{-1}$, respectively. All tests were conducted in triplet and the mean and standard deviation of collected data were reported.

\subsubsection{Seed concentration in reaction zone}

The concentrations of $\mathrm{PO}_{4}^{3-}-\mathrm{P}, \mathrm{NH}_{4}^{+}-\mathrm{N}$ and $\mathrm{pH}$ of synthetic wastewater were $60.4 \pm 1.48 \mathrm{mg} \mathrm{L}^{-1}, 81.6 \pm$ $0.99 \mathrm{mg} \mathrm{L}^{-1}$ and $9.63 \pm 0.02$, respectively. The operating temperature ranged $16.2-17.5^{\circ} \mathrm{C}$ and the molar ratio of $\mathrm{Mg} / \mathrm{PO}_{4}^{3-}-\mathrm{P}$ was at $1.54 \pm 0.04$ with magnesium solution of $0.25 \mathrm{~mol} \mathrm{~L}^{-1}$. The influent flow rate was fixed at $1.25 \mathrm{~L} \mathrm{~h}^{-1}$. Four seed concentrations, $0.12 \pm 0.03,0.30 \pm$ $0.05,0.5 \pm 0.1$, and $1.20 \pm 0.1 \mathrm{~g} \mathrm{~L}^{-1}$, were kept in the reaction zone.

\subsubsection{Molar ratio of $\mathrm{Mg} / \mathrm{PO}_{4}^{3-}-\mathrm{P}$}

Six $\mathrm{Mg} / \mathrm{PO}_{4}^{3-}-\mathrm{P}$ molar ratios, 1.03:1, 1.12:1, 1.22:1,

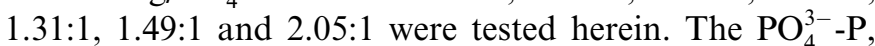
$\mathrm{NH}_{4}^{+}-\mathrm{N}$ concentration and $\mathrm{pH}$ was $53.0 \pm 0.14 \mathrm{mg} \mathrm{L}^{-1}$, $81.2 \pm 0.79 \mathrm{mg} \mathrm{L}^{-1}$ and $9.59 \pm 0.02$, respectively. The operating temperature was $12.0-16.5^{\circ} \mathrm{C}$, the seed concentration in reaction zone was kept in $0.4-1.0 \mathrm{~g} \mathrm{~L}^{-1}$, the influent flow rate was fixed at $1.25 \mathrm{~L} \mathrm{~h}^{-1}$, and the molar ratio of $\mathrm{Mg} / \mathrm{PO}_{4}^{3-}-\mathrm{P}$ was achieved accurately to some extent with magnesium solution of $0.04 \mathrm{~mol} \mathrm{~L}^{-1}$.

\subsubsection{Total hydraulic retention time (THRT)}

THRT included reaction time and precipitation time, the ratio of reaction time to precipitation time was 0.14 .
Six THRTs of 4.56, 2.28, 1.71, 1.14, 0.76 and $0.57 \mathrm{~h}$ were obtained by adjusting the flow rate of influent, with the respective $\mathrm{PO}_{4}^{3-}-\mathrm{P}, \mathrm{NH}_{4}^{+}-\mathrm{N}$ concentrations and $\mathrm{pH}$ of $52.4 \pm 0.40 \mathrm{mg} \mathrm{L}^{-1}, 81.6 \pm 0.59 \mathrm{mg} \mathrm{L}^{-1}$ and $9.56 \pm 0.03$. The operating temperature was $16.2-18.2^{\circ} \mathrm{C}$, the seed concentration in reaction zone was kept in $0.4-1.0 \mathrm{~g} \mathrm{~L}^{-1}$, and the molar ratio of $\mathrm{Mg} / \mathrm{PO}_{4}^{3-}-\mathrm{P}$ of $1.73 \pm 0.05$ was achieved with magnesium solution of $0.25 \mathrm{~mol} \mathrm{~L}^{-1}$.

\subsection{Sampling and analysis methods}

Four samples were taken at $1.0 \mathrm{~h}$ interval in each batch test and measured up to steady-state being reached. The concentrations of $\mathrm{NH}_{4}^{+}-\mathrm{N}$ and $\mathrm{PO}_{4}^{3-}-\mathrm{P}$ were analyzed according to Standard Methods (APHA, 1998). The suspension $\mathrm{pH}$ was measured using PHS-3C type $\mathrm{pH}$ meter (Shanghai Weiye Instrument Plant, China). Seed concentration in reaction zone was sampled and filtered through $0.45-\mu \mathrm{m}$ filter paper. The filtered crystals were dried at $55^{\circ} \mathrm{C}$ before weighing.

\section{Results and discussion}

\subsection{Preliminary test}

Table 2 lists the phosphorus and ammonium recovery by IRSR under different conditions.

The tests with seeds (runs 1, 3, and 5) removed more phosphorus than those without seeds and their effluent concentrations of phosphorus were lower than the corresponding control tests (runs 2, 4, and 6). Hence, seeding crystal via internal loop enhanced phosphorus recovery, since the higher the supersaturation ratio of solution was, the shorter induction time needs and the higher growth rate of struvite was (Kofina and Koutsoukos, 2005). In addition, once a seeded struvite crystallization reaction was underway in a supersaturation ratio solution, the new smaller MAP crystals could be used as the seed (Adnan et al., 2004). Thus the enhancement with seeding was $19 \%$ at low (comparison of runs 1 and 2), $6 \%$ at medium (comparison of runs 3 and 4 ) and less than $1 \%$ at high phosphorus and ammonium feeding levels (comparison of

Table 1

Characteristics of synthetic wastewater and operating conditions in the experiments of determination on the effect of IRSR

\begin{tabular}{|c|c|c|c|c|c|c|c|c|}
\hline \multirow[t]{3}{*}{ Run } & \multicolumn{3}{|c|}{ Characteristics of synthetic wastewater } & \multicolumn{5}{|c|}{ Operating conditions } \\
\hline & \multirow{2}{*}{$\mathrm{PO}_{4}^{3-}-\mathrm{P}\left(\mathrm{mg} \mathrm{L}^{-1}\right)$} & \multirow[t]{2}{*}{$\mathrm{NH}_{4}^{+}-\mathrm{N}\left(\mathrm{mg} \mathrm{L}^{-1}\right)$} & \multirow[t]{2}{*}{$\overline{\mathrm{pH}}$} & \multicolumn{2}{|c|}{ Molar ratio } & \multirow[t]{2}{*}{$T /{ }^{\circ} \mathrm{C}$} & \multicolumn{2}{|c|}{ Air flow ${ }^{\mathrm{a}} / \mathrm{L} \mathrm{h}^{-1}$} \\
\hline & & & & $\mathrm{Mg} / \mathrm{P}$ & $\mathrm{N} / \mathrm{P}$ & & Main pipe & Sub pipes ${ }^{b}$ \\
\hline 2 & 21.7 & 40.0 & 9.54 & 2.85 & 4.07 & $9.5-10$ & $2-3$ & $(3-4) \times 3$ \\
\hline 3 & 54.1 & 83.6 & 9.68 & 1.71 & 3.42 & $10.5-11$ & $11-12$ & $(1-2) \times 3$ \\
\hline 4 & 54.1 & 83.6 & 9.68 & 1.71 & 3.42 & $9.5-10$ & $2-3$ & $(3-4) \times 3$ \\
\hline
\end{tabular}

${ }^{\text {a }}$ When the air flow of main pipe was above $10 \mathrm{~L} \mathrm{~h}^{-1}$, the crystals could be lift continuously in this IRSR.

b There were three sub pipes in IRSR. 
Table 2

Different phosphorus recovery effects between seeding crystals or not in IRSR

\begin{tabular}{|c|c|c|c|c|c|}
\hline \multirow[t]{2}{*}{ Run } & \multicolumn{2}{|c|}{ Effluent of IRSR $\left(\mathrm{mg} \mathrm{L}^{-1}\right)$} & \multicolumn{3}{|c|}{ Removal amounts $\left(\mathrm{mmol} \mathrm{L}^{-1}\right)^{\mathrm{a}}$} \\
\hline & $\mathrm{PO}_{4}^{3-}-\mathrm{P}$ & $\mathrm{NH}_{4}^{+}-\mathrm{N}$ & $\mathrm{pH}$ & $\mathrm{PO}_{4}^{3-}-\mathrm{P}$ & $\mathrm{NH}_{4}^{+}-\mathrm{N}$ \\
\hline 1 & $4.71 \pm 0.09$ & $31.9 \pm 0.38$ & $9.13 \pm 0.03$ & $0.55 \pm 0.003$ & $0.57 \pm 0.03$ \\
\hline 2 & $8.82 \pm 0.14$ & $34.1 \pm 0.40$ & $9.28 \pm 0.04$ & $0.41 \pm 0.004$ & $0.42 \pm 0.03$ \\
\hline 3 & $4.22 \pm 0.24$ & $55.2 \pm 0.46$ & $8.97 \pm 0.04$ & $1.61 \pm 0.008$ & $2.02 \pm 0.03$ \\
\hline 4 & $7.49 \pm 0.23$ & $56.2 \pm 0.44$ & $9.09 \pm 0.02$ & $1.50 \pm 0.007$ & $1.95 \pm 0.03$ \\
\hline 5 & $0.32 \pm 0.08$ & $4460 \pm 30$ & $9.18 \pm 0.005$ & $4.94 \pm 0.003$ & $7.30 \pm 2.17$ \\
\hline 6 & $1.05 \pm 0.26$ & $4450 \pm 28$ & $9.18 \pm 0.005$ & $4.92 \pm 0.008$ & $8.08 \pm 2.02$ \\
\hline
\end{tabular}

${ }^{a}$ Removal amount $\left(\mathrm{mmol} \mathrm{L}^{-1}\right)=$ (influent concentration-effluent concentration)/molecular weight of $\mathrm{P} \& \mathrm{~N}$.

runs 5 and 6), which represented low, medium and high supersaturation ratio solution, respectively. Adnan et al. (2004) claimed that the MAP process was not cost effective at low phosphorus influent concentration $\left(20-30 \mathrm{mg} \mathrm{L}^{-1}\right)$. The proposed IRSR, on the contrary, revealed a high phosphorus recovery rate of $78 \%$ at influent phosphorus concentration of only $21.7 \mathrm{mg} \mathrm{L}^{-1}$ (run 1) because that the recycle seeding could enhance the MAP reaction rate, increase crystal size and improve crystal settleability. Such an observation indicates the significant potential to apply IRSR in phosphorus recovery from domestic wastewater. The advantage of applying IRSR, however, diminished at high supersaturation ratio solution, such as higher $\mathrm{PO}_{4}^{3-}$ $\mathrm{P}$ concentration, higher molar ratio of $\mathrm{N} / \mathrm{P}$ and $\mathrm{Mg} / \mathrm{P}$ etc., like the synthetic wastewater used in runs 5 and 6 .

\subsection{Operation performance}

Seeding enhances MAP crystals growth in the reaction zone, meanwhile, it also costs energy ( $\mathrm{Wu}$ and Bishop, 2004). As Fig. 2 shows, the residual phosphorus concentrations were all less than $7 \mathrm{mg} \mathrm{L}^{-1}$ over seeding concentration of $0.15-1.2 \mathrm{~g} \mathrm{~L}^{-1}$, with the minimum residual

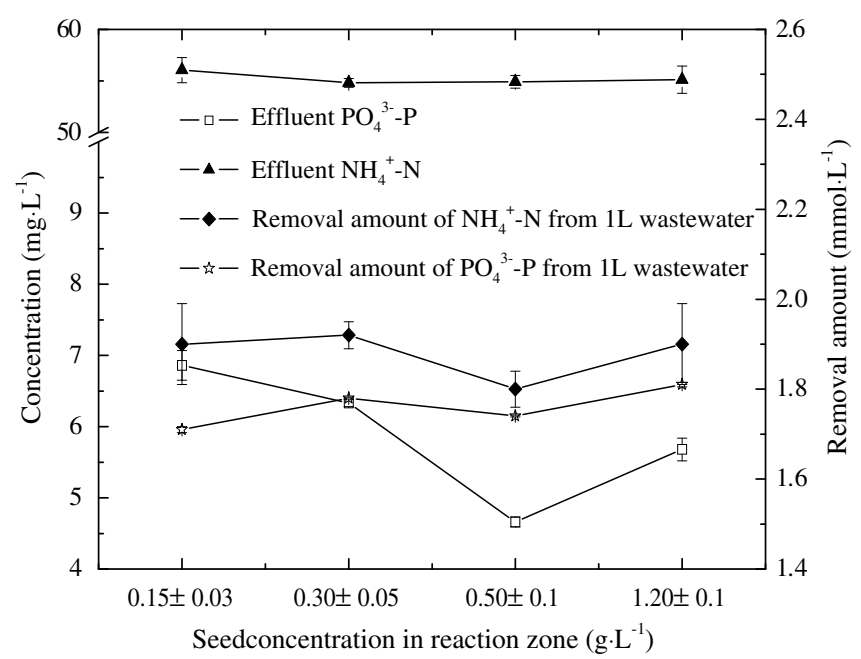

Fig. 2. Correlation between seeds quantities and effluent concentrations and removal amounts from IRSR. (THRT $=2.28 \mathrm{~h}$, initial $\mathrm{PO}_{4}^{3-}$ $\mathrm{P}=60.4 \pm 1.48 \mathrm{mg} \mathrm{L}^{-1}, \mathrm{NH}_{4}^{+}-\mathrm{N}=81.6 \pm 0.99 \mathrm{mg} \mathrm{L}^{-1}, \mathrm{pH}=9.63 \pm 0.02$, temperature $=16.2-17.5^{\circ} \mathrm{C}, \mathrm{Mg} / \mathrm{PO}_{4}^{3-}-\mathrm{P}=1.54 \pm 0.04$.) phosphorus concentration was achieved at seed concentration of $0.50 \mathrm{~g} \mathrm{~L}^{-1}$. However, the noted differences from tests of different seeding concentration were not significant. A low recirculation rate in the loop that acquires minimum energy input but still performs well is considered. In addition, considering the difficulty of controlling a constant seed concentration of $0.50 \mathrm{~g} \mathrm{~L}^{-1}$ in practical use, the seed concentration of $0.40-1.0 \mathrm{~g} \mathrm{~L}^{-1}$ was suggested as optimum amount in reaction zone of IRSR.

High molar ratio of $\mathrm{Mg} / \mathrm{PO}_{4}^{3-}-\mathrm{P}$ yields high phosphorus recovery based on chemical equilibrium calculation, but produces high chemical cost. The residual phosphorus concentrations from IRSR were less than $10 \mathrm{mg} \mathrm{L}^{-1}$ at molar ratio of $\mathrm{Mg} / \mathrm{PO}_{4}^{3-}-\mathrm{P}$ greater than the stoichiometric ratio of 1:1 (Fig. 3). However, again, increasing this molar ratio only yielded incremental increase in phosphorus recovery. A molar ratio of $\mathrm{Mg} / \mathrm{PO}_{4}^{3-}-\mathrm{P}$ of $1.3-1.5: 1$ could be selected for IRSR operation considering minimum use of chemicals.

The phosphorus recovery increased with increasing total hydraulic retention time (THRT) of IRSR. No further improvement was achieved at THRT $>1.14 \mathrm{~h}(8.4 \mathrm{~min}$ for reaction and $60 \mathrm{~min}$ for settling) (Fig. 4). Even with a reduced TRHT of $0.57 \mathrm{~h}$, the residual phosphorus

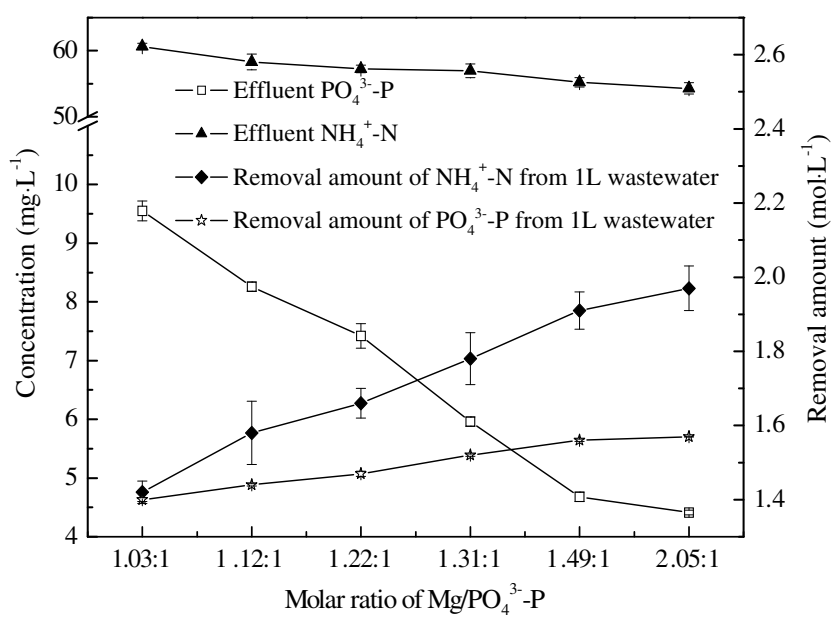

Fig. 3. Correlation between $\mathrm{Mg} / \mathrm{PO}_{4}^{3-}-\mathrm{P}$ molar ratio and effluent concentrations and removal amounts from IRSR. (THRT $=2.28 \mathrm{~h}$, initial $\mathrm{PO}_{4}^{3-}$ $\mathrm{P}=53.0 \pm 0.14 \mathrm{mg} \mathrm{L}^{-1}, \mathrm{NH}_{4}^{+}-\mathrm{N}=81.2 \pm 0.79 \mathrm{mg} \mathrm{L}^{-1}, \mathrm{pH}=9.59 \pm 0.02$, temperature $=12.0-16.5^{\circ} \mathrm{C}$, seed concentration in reaction zone $=0.4$ $1.0 \mathrm{~g} \mathrm{~L}^{-1}$.) 


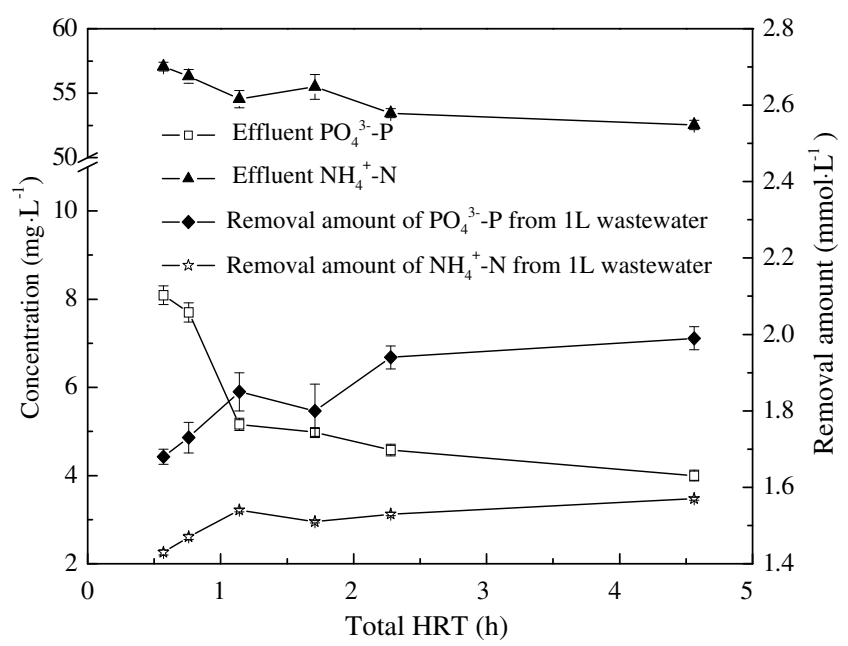

Fig. 4. Correlation between THRT and effluent concentrations and removal amounts from IRSR. (Initial $\mathrm{PO}_{4}^{3-}-\mathrm{P}=52.4 \pm 0.40 \mathrm{mg} \mathrm{L}^{-1}$, $\mathrm{NH}_{4}^{+}-\mathrm{N}=81.6 \pm 0.09 \mathrm{mg} \mathrm{L}^{-1}, \quad \mathrm{pH}=9.56 \pm 0.03$, temperature $=16.2-$ $18.2^{\circ} \mathrm{C}$, seed concentration in reaction zone $=0.4-1.0 \mathrm{~g} \mathrm{~L}^{-1}$, $\mathrm{Mg} / \mathrm{PO}_{4}^{3-}-\mathrm{P}=1.73 \pm 0.05$.)

concentration was less than $10 \mathrm{mg} \mathrm{L}^{-1}$. The proposed IRSR could thereby be designed in a compact manner in domestic wastewater treatment plant.

Two disadvantages were noted in the tests for proposed IRSR. Firstly, in all herein reported tests, the removal quantities of $\mathrm{NH}_{4}^{+}-\mathrm{N}$ exceeded those of $\mathrm{PO}_{4}^{3-}-\mathrm{P}$ based on the stoichiometric ratio of 1:1 for MAP. Since the loss of ammonium increased with increasing THRT and initial ammonium concentrations (Fig. 4, Table 2), such an occurrence may be attributable to stripping loss at alkaline condition. The stripping loss of $\mathrm{NH}_{4}^{+}-\mathrm{N}$ may be minimized with the revised feeding strategy by Kim et al. (2007). Secondly, during the tests, certain amount of fine crystals would attach to the reactor's wall and could be flushed out with effluent. Le Corre et al. (2007a) coagulated the fines from their reactor to reduce this loss. A collection device as proposed by Suzuki et al. (2007) and Le Corre et al. (2007b) may be applicable to the present IRSR. Further studies are needed to justify these improvement strategies.

\section{Conclusions}

A new MAP reactor, the IRSR, which comprises a reaction zone and a settling zone, was proposed to enhance phosphorus recovery from wastewater stream containing low levels of phosphorus. A recirculation loop providing seed crystals from reaction zone promote secondary nucleation rate of MAP. This proposed MAP reactor increased phosphorus recovery efficiency by $19 \%$ at low phosphorus influent concentrations, but revealed similar performance at high phosphorus influent concentrations compared with the non-seeded reactor. Performance tests showed that the proposed MAP reactor could achieve sufficient phosphorus recovery using seeding concentration of $0.4-1.0 \mathrm{~g} \mathrm{~L}^{-1}$, molar ratio of $\mathrm{Mg} / \mathrm{PO}_{4}^{3-}-\mathrm{P}$ of $1.3-1.5: 1$, and THRT $>1.14 \mathrm{~h}$. On the other hand, two disadvantages, including ammonium stripping loss and fine MAP crystals loss remain unresolved for the proposed IRSR.

\section{References}

Adnan, A., Mavinic, D.S., Koch, F.A., 2003. Pilot-scale study of phosphorus recovery through struvite crystallization - examining the process feasibility. Environ. Eng. Sci. 2, 315-324.

Adnan, A., Dastur, M., Mavinic, D.S., Koch, F.A., 2004. Preliminary investigation into factors affecting controlled struvite crystallization at the bench scale. J. Environ. Eng. Sci. 3, 195-202.

Altinbas, M., Yangin, C., Ozturk, I., 2002. Struvite precipitation from anaerobically treated municipal and landfill wastewaters. Water Sci. Technol. 46, 271-278.

APHA, 1998. Standard Methods for the Examination of Water and Wastewater, 19th ed. American Public Health Association/American Water Works Association/Water Environment Federation, Washington, DC, USA.

Ban, Z., Dave, G., 2004. Laboratory studies on recovery of $\mathrm{N}$ and $\mathrm{P}$ from human urine through struvite crystallisation and zeolite adsorption. Environ. Technol. 25, 111-121.

Battistoni, P., Pavan, P., Prisciandaro, M., Cecchi, F., 2000. Struvite crystallization: a feasible and reliable way to fix phosphorus in an aerobic supernatants. Water Res. 34, 3033-3041.

Battistoni, P., De Angelis, A., Pavan, P., Prisciandaro, M., Cecchi, F., 2001. Phosphorus removal from a real anaerobic supernatant by struvite crystallization. Water Res. 35, 2167-2178.

Battistoni, P., De Angelis, A., Prisciandaro, M., Boccadoro, R., Bolzonella, D., 2002. P removal from anaerobic supernatants by struvite crystallization: long term validation and process modelling. Water Res. 36, 1927-1938.

Battistoni, P., Boccadoro, R., Fatone, F., Pavan, P., 2005. Autonucleation and crystal growth of struvite in a demonstrative fluidised bed reactor (FBR). Environ. Technol. 26, 975-982.

Burns, R.T., Moody, L.B., Celen, I., Buchanan, J.R., 2003. Optimization of phosphorus precipitation from swine manure slurries to enhance recovery. Water Sci. Technol. 48, 139-146.

Chimenos, J.M., Fernandez, A.I., Villalba, G., Segarra, M., Urruticoechea, A., Artaza, B., Espiell, F., 2003. Removal of ammonium and phosphates from wastewater resulting from the process of cochineal extraction using MgO-containing by-product. Water Res. 37, 16011607.

de-Bashan, L.E., Bashan, Y., 2004. Recent advances in removing phosphorus from wastewater and its future use as fertilizer (19972003). Water Res. 38, 4222-4246.

Doyle, J.D., Parsons, S.A., 2002. Struvite formation, control and recovery. Water Res. 36, 3925-3940.

Jaffer, Y., Clark, T.A., Pearce, P., Parsons, S.A., 2002. Potential phosphorus recovery by struvite formation. Water Res. 36, 1834-1842.

Kabdaşli, I., Parsons, S.A., Tünay, O., 2006. Effect of major ions on induction time of struvite precipitation. Croat. Chem. Acta 79, 243 251.

Kim, B.U., Lee, W.H., Lee, H.J., Rim, J.M., 2004. Ammonium nitrogen removal from slurry-type swine wastewater by pretreatment using struvite crystallization for nitrogen control of anaerobic digestion. Water Sci. Technol. 49, 215-222.

Kim, D., Ryu, H.D., Kim, M.S., Kim, J., Lee, S.I., 2007. Enhancing struvite precipitation potential for ammonia nitrogen removal in municipal landfill leachate. J. Hazard. Mater. doi:10.1016/ j.jhazmat.2006.11.054.

Kofina, A.N., Koutsoukos, P., 2005. Spontaneous precipitation of struvite from synthetic wastewater. Cryst. Growth Des. 5, 489-496.

Le, Z., Li, X.M., 2006. Nutrient removal from anaerobically digested cattle manure by struvite precipitation. J. Environ. Eng. Sci. 5, 285-294. 
Le Corre, K.S., Valsami-Jones, E., Hobbs, P., Parsons, S.A., 2005. Impact of calcium on struvite crystal size, shape and purity. J. Cryst. Growth 283, 514-522.

Le Corre, K.S., Valsami-Jones, E., Hobbs, P., Jefferson, B., Parsons, S.A., 2007a. Agglomeration of struvite crystals. Water Res. 41, 419-425.

Le Corre, K.S., Valsami-Jones, E., Hobbs, P., Jefferson, B., Parsons, S.A., 2007b. Struvite crystallisation and recovery using a stainless steel structure as a seed material. Water Res. doi:10.1016/j.watres. 2007.03.002.

Lee, S.I., Weon, S.Y., Lee, C.W., Koopman, B., 2003. Removal of nitrogen and phosphate from wastewater by addition of bittern. Chemosphere 51, 265-271.

Lee, C.W., Kwon, H.B., Kim, Y.J., Jeon, H.P., 2005. Nutrients recovery by struvite formation from wastewater in a fluidized bed reactor. Eco-Mater. Process. \& Design Vi Mater. Sci. Forum 486-487, 387 390.

Li, X.Z., Zhao, Q.L., 2002. MAP precipitation from landfill leachate and seawater bittern waste. Environ. Technol. 23, 989-1000.

Li, X.Z., Zhao, Q.L., 2003. Recovery of ammonium-nitrogen from landfill leachate as a multi-nutrient fertilizer. Ecol. Eng. 20, 171-181.

Mijangos, F., Kamel, M., Lesmes, G., Muraviev, D.N., 2004. Synthesis of struvite by ion exchange isothermal supersaturation technique. React. Funct. Polym. 60, 151-161.

Ohlinger, K.N., Young, T.M., Schroeder, E.D., 1998. Predicting struvite formation in digestion. Water Res. 32, 3607-3614.

Ohlinger, K.N., Young, T.M., Schroeder, E.D., 1999. Kinetics effects on preferential struvite accumulation in wastewater. J. Environ. Eng. 125, 730-737.

Quintana, M., Colmenareio, M.F., Barrera, J., Garcia, G., Garcia, E., Bustos, A., 2004. Use of a byproduct of magnesium oxide production to precipitate phosphorus and nitrogen as struvite from wastewater treatment liquors. J. Agr. Food. Chem. 52, 294-299.
Shimamura, K., Homma, Y., Watanabe, A., Tanaka, T., 2001. Research on MAP recovery conditions using a fluidized-bed crystallized phosphorus removal system. Asian Waterqual., 843-848.

Shimamura, K., Tannka, T., Miura, Y., Ishikawa, H., 2003. Development of a high-efficiency phosphorus recovery method using a fluidized-bed crystallized phosphorus removal system. Water Sci. Technol. 48, 163170.

Steen, I., 1998. Phosphorus availability in the 21 st century management of a non-renewable resource. Phosphorus and Potassium 217, 25-31.

Stratful, I., Scrimshaw, M.D., Lester, J.N., 2004. Removal of struvite to prevent problems associated with its accumulation in wastewater treatment works. Water Environ. Res. 76, 437-443.

Suzuki, K., Tanaka, Y., Kuroda, K., Hanajima, D., Fukumoto, Y., Yasuda, T., Waki, M., 2007. Removal and recovery of phosphorus from swine wastewater by demonstration crystallization reactor and struvite accumulation device. Bioresour. Technol. 98, 1573-1578.

Tunay, C., Zengin, G.E., Kabdash, I., Karahan, O., 2004. Performance of magnesium ammonium phosphate precipitation and its effect on biological treatability of leather tanning industry wastewaters. J. Environ. Sci. Heal Part A-Toxic/Hazardous Substances \& Environ. Eng. 39, 1891-1902.

Wang, J., Burken, J.G., Zhang, X.Q., 2006. Effect of seeding materials and mixing strength on struvite precipitation. Water Environ. Res. 78, 125132.

Wu, Q.Z., Bishop, P.L., 2004. Enhancing struvite crystallization from anaerobic supernatant. J. Environ. Eng. Sci. 3, 21-29.

Yang, H.X., Sun, H.J., 2004. Crystal structure of a new phosphate compound, $\mathrm{Mg}_{2} \mathrm{KNa}\left(\mathrm{PO}_{4}\right)_{2} \cdot 14 \mathrm{H}_{2} \mathrm{O}$. J. Solid State Chem. 177, 29912997.

Yoshino, M., Yao, M., Tsuno, H., Somlya, I., 2003. Removal and recovery of phosphate and ammonium as struvite from supernatant in anaerobic digestion. Water Sci. Technol. 48, 171-178. 